\title{
Reduction of elasmobranch by-catch in the hake semipelagic near-bottom longline fishery in the Algarve (Southern Portugal)
}

\author{
Rui COELHO, ${ }^{*}$ Luís BENTES, Jorge Ms GONÇALVES, Pedro G LINO, JoAQuim RIBEIRO AND \\ KARIM ERZINI
}

Universidade do Algarve, CCMAR/FCMA, Campus de Gambelas, 8000-117 Faro, Portugal

\begin{abstract}
Elasmobranch fish, particularly deep-sea sharks, are the most important component of the by-catch of the hake semipelagic near-bottom 'pedra-e-bola' longline fishery in the Algarve (South Portugal) and most of these fish are discarded. The effects of the removal of the lower hooks were evaluated, in terms of target and by-catch reductions, by quantifying the catches of each hook relative to the distance from the bottom. The analysis showed that most European hake (Merluccius merluccius), the target species of this fishery, were caught in the middle range of the hooks, with very few individuals caught near the bottom, whereas for sharks the situation was the opposite, with most hooked near the bottom. The removal of the lower three pairs of hooks would result in a small reduction in the catch of the target species, but a much more significant reduction in elasmobranch by-catch. In the specific case of the blackmouth catshark (Galeus melastomus), discard mortality would be further minimized due to the fact that the lower hooks capture significantly smaller animals that are always discarded compared with hooks that are more distant from the bottom.
\end{abstract}

KEY WORDS: by-catch reduction, hake, longline, Portugal, shark.

\section{INTRODUCTION}

Longlines, along with gill nets and trammel nets, are the most widely used and important gears in the artisanal fisheries of Portugal. In the Algarve, of the 4088 commercial fishing licenses issued in 1998, 1116 (27.3\%) were for longlines, with 920 for the 'local' category boats ( $<9 \mathrm{~m}$ in length and generally powered with an outboard engine) and 196 for the larger 'coastal' category boats ( $>9 \mathrm{~m}$ and up to 180 gross registered tonnage (GRT)). ${ }^{1}$ In contrast with gill nets and trammel nets, where legislation concerning maximum stretched mesh size and maximum length of nets exists, there is no legislation regulating maximum length, minimum hook size or the number of hooks used in the longlines.

In Portugal, European hake (Merluccius merluccius) landings peaked at 10400 ton in 1975 and have been decreasing since, reaching 2978 ton in 2000. Due to concerns about the spawning biomass and recruitment, total allowable catch (TAC) for the Southern stock have been consecutively set lower, from 29300 ton in 1986 to 9000 ton in

*Corresponding author: Tel.: 351-289-800-900.

Fax: 351-289-818-353. Email: rpcoelho@ualg.pt

Received 30 April 2002. Accepted 3 October 2002.
$1996,{ }^{2}$ and a $27 \mathrm{~cm}$ total length minimum size established.

Sharks are an important component of the bycatch of the hake longline fishery and, depending on species, size and season of year, they can either be commercialized or discarded. In recent years, a number of cases of overexploitation in shark fisheries have been documented, ${ }^{3-6}$ as well as high levels of by-catch in other fisheries ${ }^{7,8}$ and the effect of other fishing activities, such as recreational fishing. ${ }^{9}$ Due to their slow growth rates, ${ }^{10,11}$ low fecundity with delayed reproductive effort geared towards the production of small numbers of progeny after a long gestation period, ${ }^{12-14}$ these fish are highly susceptible to overexploitation.

Some studies have already related catch with height of hooks in a vertical longline. ${ }^{15,16}$ In Portugal, and especially in the Algarve, previous studies on the longline fishery focused mainly on species composition, catch rates and size selectivity ${ }^{17-21}$ To date, there have been no studies on ways to reduce by-catch of discard species in Portuguese longline fisheries. The aim of the present study was to evaluate ways of reducing elasmobranch by-catch, particularly in the size range where animals are discarded, while minimizing the reduction in the catches of the target species, the European hake. 


\section{MATERIALS AND METHODS}

Fishing trials with the semipelagic near-bottom longlines ${ }^{22}$ were performed in 1998, between May and August, along the south coast of Portugal (Algarve). The 10 fishing trials were performed by a commercial longliner that usually operates in these waters and the fishing took place on traditional fishing grounds at depths between 200 and $550 \mathrm{~m}$, mainly on muddy bottoms (Fig. 1).

The semipelagic near-bottom longline used consisted of a $1.60-\mathrm{mm}$ diameter monofilament main line with $0.90-\mathrm{mm}$ diameter monofilament gangions (snoods) of approximately $1.2 \mathrm{~m}$ attached, without swivels, directly to the main line at intervals of approximately $1.8 \mathrm{~m}$. The longline was lifted off the bottom by glass balls ('bolas') at intervals of 40 hooks and weighted down with small rocks ('pedras') inbetween (Fig. 2). Hooks were numbered from 1 to 40 , starting at the small rock, and the glass ball was located between hooks number 20 and 21 . Therefore, hooks number 1 and 40 were nearer to the bottom and hooks number
20 and 21 further from the bottom, with the distance relative to the bottom increasing from hook 1 until hook 20 and then decreasing from hook 21 until hook 40. Catches of hooks at the same distances relative to the bottom were grouped in pairs (e.g. pair $1=$ hooks $1+40$, pair $2=$ hooks $2+39$, pair $3=$ hooks $3+38$ etc.).

The longlines were stored in plastic tubs, each containing 120 hooks. After discussion with the commercial fishermen, it was decided to use four hook sizes: 10, 9, 7 and 5. The mean number of tubs used per set was 44 , with 11 tubs (1320 hooks) of each hook size. The sequence of hook sizes or tubs fished was the following: 10-5-9-7. Frozen sardines were thawed on the way to the fishing grounds and, after being cut in half, used to bait the longline. The total length of the longline was between 10 and $15 \mathrm{~km}$ and, typically, the fishing trips lasted $17-21 \mathrm{~h}$.

All hooks were registered for position, presence or absence of bait and catches at hauling. All catches were quantified by species and measurement of total length was recorded for the target

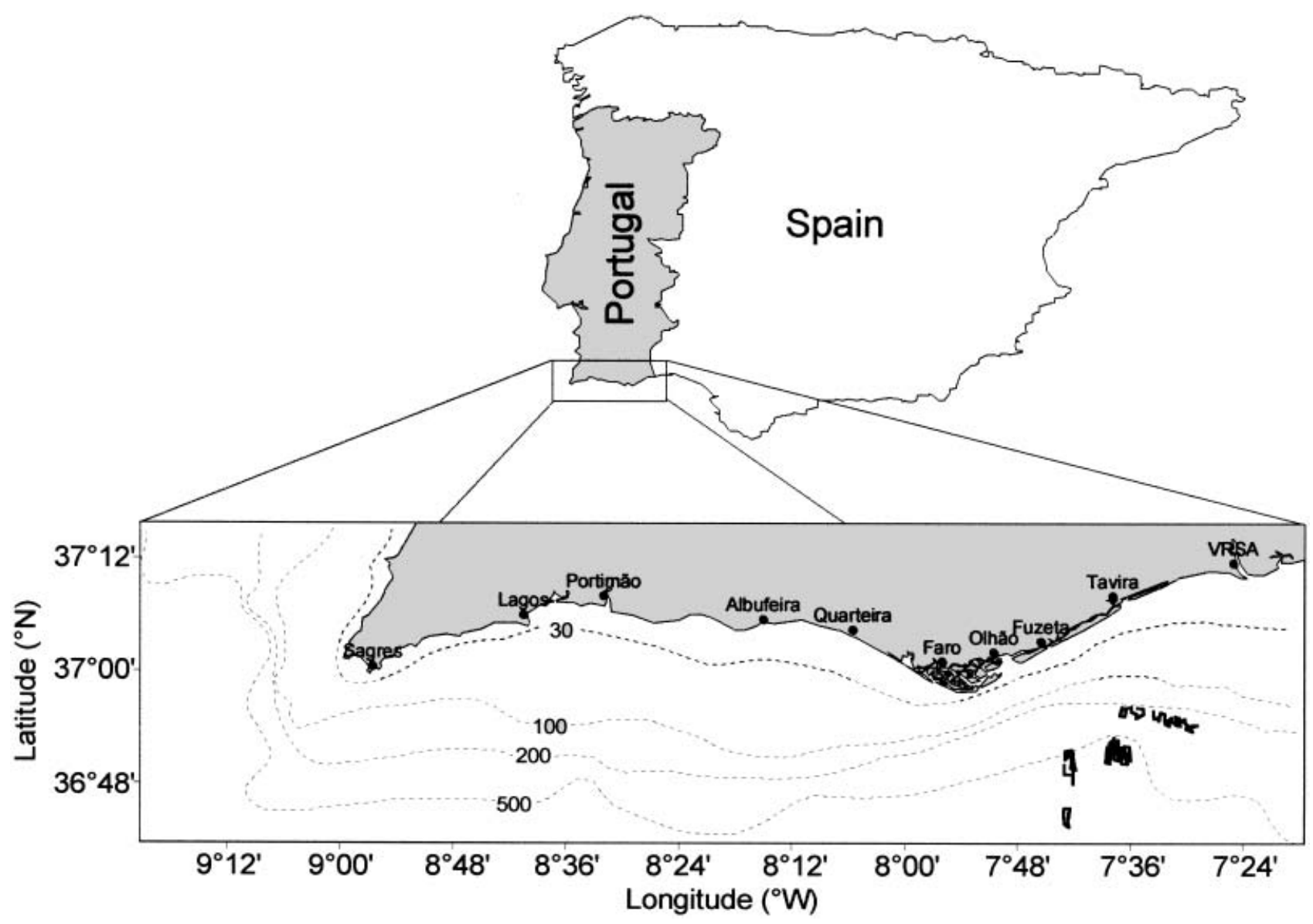

Fig. 1 Map of the Algarve with the location of the longline fishing trials. 


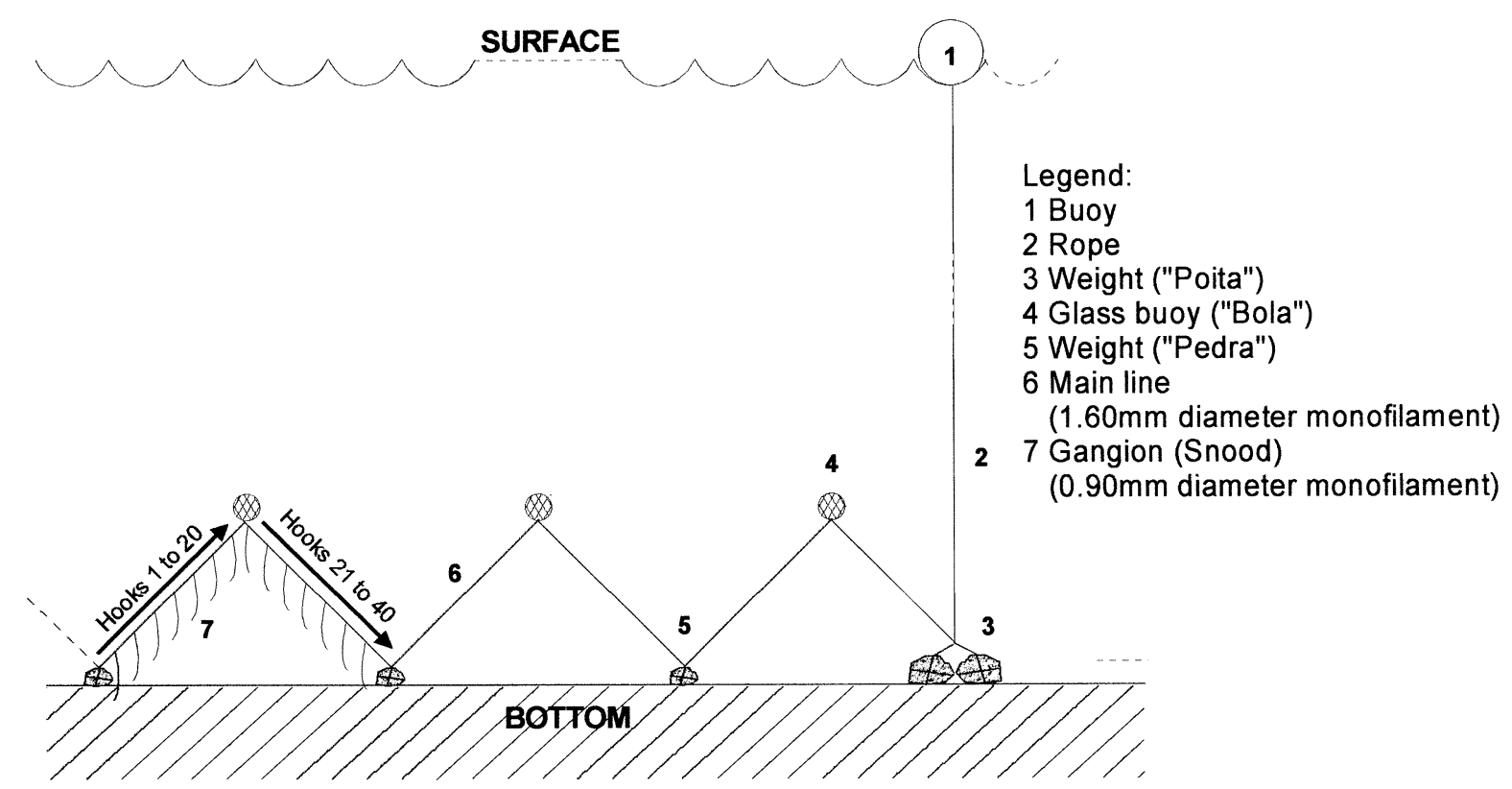

Fig. 2 Schematic representation of the semipelagic near-bottom longline ('pedra-e-bola') used in the present study.

species, the European hake, and the most important elasmobranch species, the blackmouth catshark (Galeus melastomus), in order to evaluate whether there were significant differences in the lengths of fish captured at different distances from the bottom.

The Kruskal-Wallis test was used to see whether there were any significant differences in the mean length of captures due to hook distance from the bottom. This non-parametric test was used instead of the parametric ANOVA because of the failure of the normality assumption for the parametric test. In cases where significant differences were detected, Dunn's all pairwise multiple comparison test was used to identify which pairwise comparisons contributed to the overall difference.

A comparison of the actual captures with the simulated captures without the lower pairs of hooks was performed for both the target species and the most important elasmobranch species. This reduction of the hooks used was accomplished by withdrawing one pair of hooks at each step, starting from the bottom (lower) hooks, and only while the reduction in the captures of the target species was less than $25 \%$.

The Mann-Whitney rank sum test was used to evaluate whether significant differences occurred between the lengths of specimens captured in the lower pairs of hooks compared with those higher up in the water column. Again, this non-parametric test was used instead of the parametric
Student's $t$-test due to the failure of the assumption of normality.

\section{RESULTS}

A total of 2787 fish was caught, of which 910 (32.7\%) were from the class Elasmobranchii (five species), one was a Holocephali and the remaining 1876 (67.3\%) were Actinopterygii (19 species). The Elasmobranchii species were the blackmouth catshark Galeus melastomus, the smooth lanternshark Etmopterus pusillus, the small-spotted catshark Scyliorhinus canicula, the blue shark Prionace glauca and the smooth-hound Mustelus mustelus. The single Holocephali species was a rabbit fish (Chimaera monstrosa). The target species of this fishery, the European hake, was numerically the most important, with 1258 specimens (45.1\%), followed by the blackmouth catshark (525 specimens), the smooth lanternshark (264 specimens) and the small-spotted catshark (118 specimens). These three sharks accounted for $99.7 \%$ of the elasmobranchs and $32.5 \%$ of the total catch. The elasmobranch species have different uses, because all smooth lanternsharks were discarded $(100 \%)$, but the small-spotted catshark and the blackmouth catshark were either discarded or landed, depending on size and season of the year. Because only the larger animals are commercialized and all others discarded, we estimated that, in the case of the 


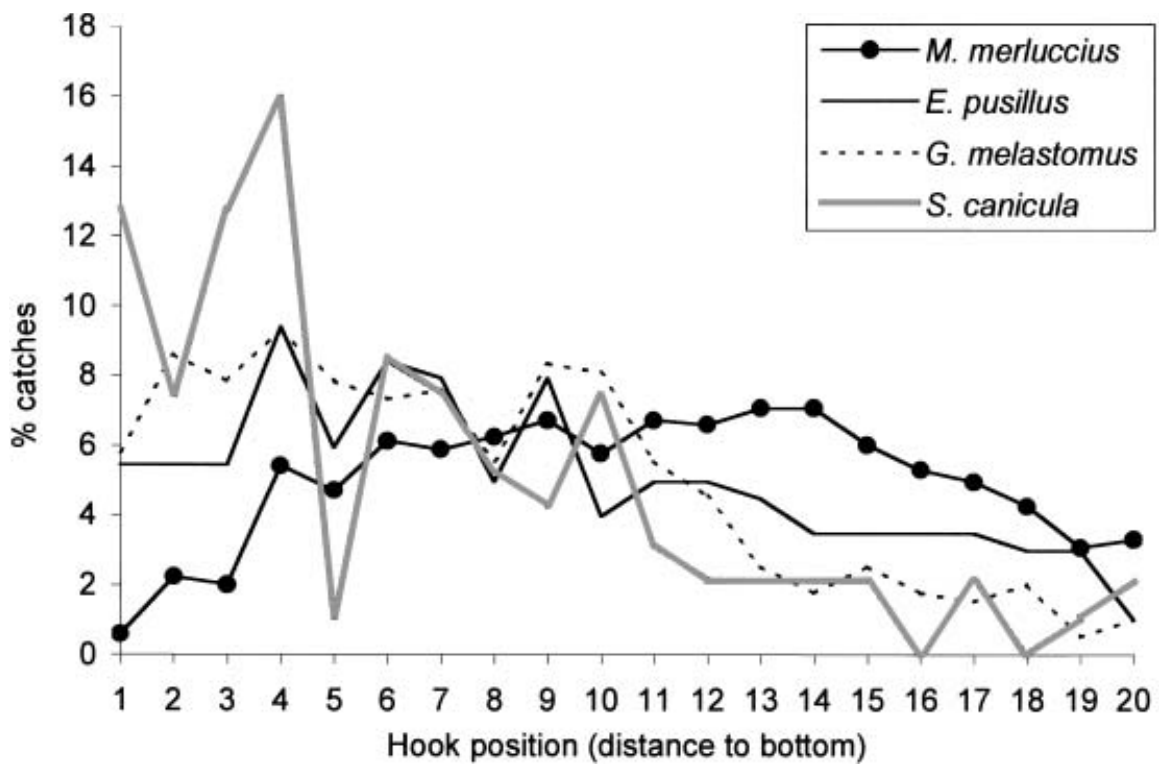

Fig. 3 Distributions of the catches of European hake and the most important elasmobranch species along the gradient relative to the distance of the hook to the bottom.

Table 1 Reduction of catches of the target species and the most important elasmobranch species when consecutive pairs of hooks (starting from the bottom) were removed; only reductions in the catches of the European hake up to $25 \%$ were considered

\begin{tabular}{lcccc}
\hline & \multicolumn{3}{c}{ Reduction in catches (\%) } \\
\cline { 2 - 5 } Pair of hooks removed & Merluccius merluccius & Galeus melastomus & Etmopterus pusillus & Scyliorhinus canicula \\
\hline 1 & 0.59 & 5.81 & 5.45 & 12.77 \\
$1-2$ & 2.89 & 14.39 & 10.89 & 20.21 \\
$1-3$ & 4.83 & 22.22 & 16.34 & 32.98 \\
$1-4$ & 10.25 & 31.57 & 25.74 & 48.94 \\
$1-5$ & 14.96 & 39.39 & 31.68 & 50.00 \\
$1-6$ & 21.08 & 46.72 & 40.10 & 58.51 \\
\hline
\end{tabular}

blackmouth catshark, $46.7 \%$ of the catch was sold as by-catch and $53.3 \%$ discarded, whereas for the small-spotted catshark only $10.3 \%$ of the catch was sold as by-catch and the remaining $89.7 \%$ was discarded.

Analysis of the catch according to the hook distance relative to the bottom revealed that for the target species, the European hake, most specimens were caught in the middle of the range, with very few individuals caught by the lower, near-bottom hooks. Analysis of elasmobranch catches revealed the opposite situation, because, for the three mostcaptured species, relatively more specimens were caught by the lower hooks (Fig. 3). Simulations of the removal of the lower hooks showed that catch reductions were much lower for the commercial European hake than for the by-catch elasmobranch species (Table 1).

Analysis of the lengths of the catches at different levels of the water column showed greater size dispersion for the blackmouth catshark than for the
European hake, with length generally increasing with height in the water column in this last species (Fig. 4). Statistical analysis showed that there were no significant differences in the mean lengths of European hakes with regard to hook height (Kruskal-Wallis $P=0.645$ ). However, for the blackmouth catshark, significant differences were detected (Kruskal-Wallis $P=0.028$ ). The pairwise multiple comparison Dunn test showed that only hooks 1 and 17 differed in mean lengths.

When the catches of the lower pairs of hooks were grouped and the mean lengths compared with those of the remaining hooks, again no significant differences were detected for the European hake (Mann-Whitney $P=0.056, \quad P=0.155, \quad P=$ 0.733, $P=0.711, P=0.877$ and $P=0.483$ for $1,2,3$, 4, 5 and 6 lower pairs of hooks, respectively), but significant differences were detected for the blackmouth catshark (Mann-Whitney $P=0.002, P=$ 0.004, $P=0.001, P<0.001, P<0.001$ and $P<0.001$ for $1,2,3,4,5$ and 6 lower pairs of hooks, respec- 


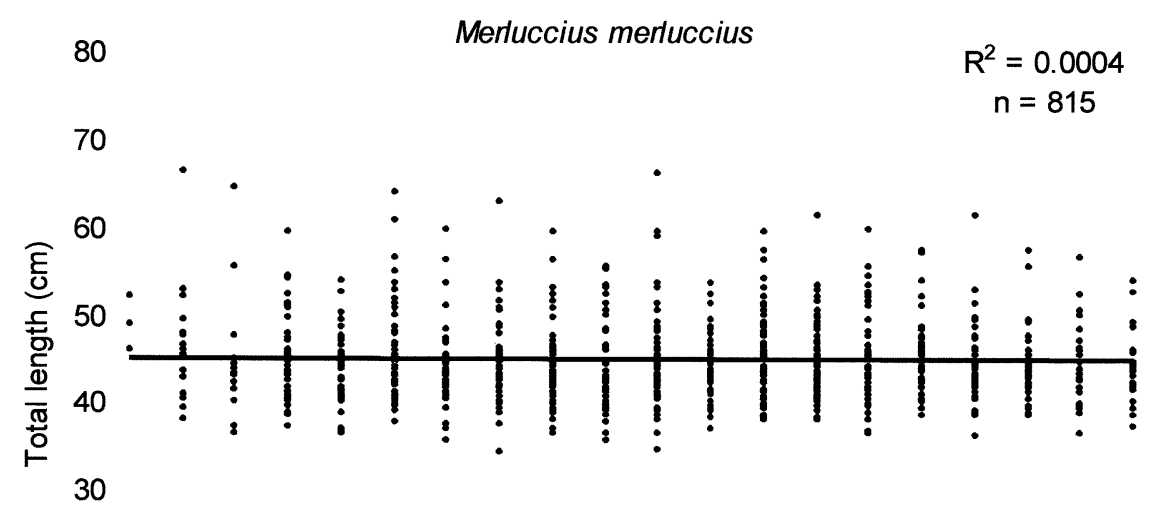

Fig. 4 Total lengths of catches of European hake and the blackmouth catshark captured at each hook position relative to the bottom ( 1 is the nearest to the bottom and 20 is the furthest from the bottom). The solid line represents the linear regression (trend line) between total length and hook position.

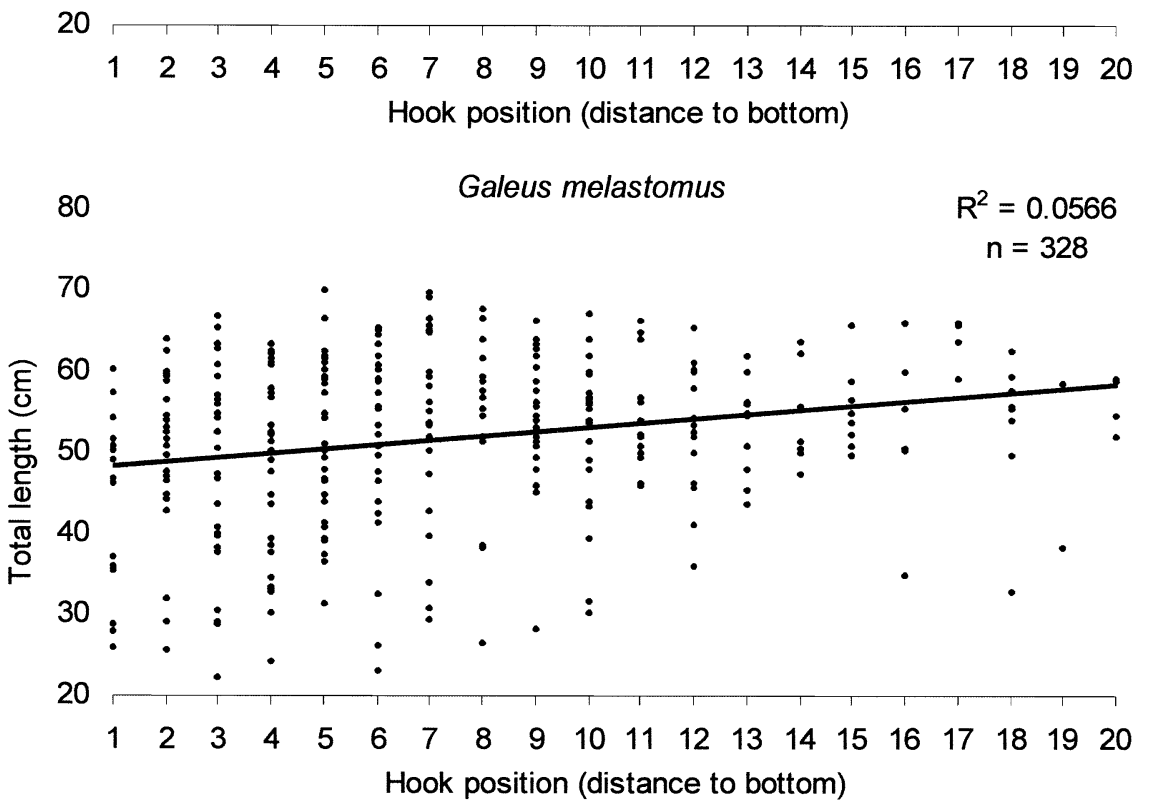

tively). In the case of the latter species, the lower hooks capture significantly smaller animals than those higher up in the water column.

\section{DISCUSSION}

Elasmobranch fish, particularly the sharks, represented the most important by-catch group of this fishery, with $32.7 \%$ of the total catches, which can be considered a high value because the target species accounted for $45.1 \%$ of the total catch.

The withdrawal of the lower three pairs of hooks in this fishery would represent a reduction of $15 \%$ of the hooks used. However, the respective catch reduction of European hake would be very low (4.8\%), whereas the corresponding reduction of elasmobranch by-catch would be much more significant, from 16.3 to $33.0 \%$ depending on the spe- cies. Russell et al. ${ }^{23}$ observed that sharks were more frequently caught near the bottom by the lower hook positions in a demersal longline, suggesting a higher abundance or close association of these animals with the bottom. These differences between the hake and the sharks may be related to feeding strategies, with these elasmobranchs being largely bottom scavengers, whereas the hake feeds mainly on fish up in the water column. ${ }^{24,25}$

More pairs of hooks could be removed with an even higher reduction of elasmobranch by-catch, but catches of the target species would also be reduced greatly. Therefore, the reduction of only the lower three pairs of hooks seems to be the more reasonable proposal, because there is a small reduction of catches of the target species with, at the same time, much more significant reductions in elasmobranch by-catch. This reduction in elasmobranch catches is very important, not only because fewer specimens are caught, but also, in 
the specific case of the blackmouth catshark, because significant differences were detected in the mean lengths of captures, with the lower hooks catching smaller animals. Given the fact that in this species only the larger animals would eventually be commercialized (depending also on the season of the year), the reduction of catches, especially in the smaller range of lengths would significantly reduce discard mortality.

Although several studies have dealt with different strategies for increasing species selectivity and decreasing by-catch rates in longline fisheries, none based on the current hook removal suggestion presented in this paper is known. Those previous studies have included strategies such as gear modifications (use of alternative hook and bait types) and fishing strategies (increased sinking rates of the longlines), ${ }^{22,26,27}$ as well as area and time restrictions. ${ }^{28}$ Matsuoka et al..$^{29}$ proposed reducing fish loss and potential fish injury by using more hooks on the lower positions, where catch is maximized while, at the same time, reducing soak time of the longline. This suggestion is efficient only when catches of the target species are associated with the lower hooks and not in the present case, where very few European hakes are caught near the bottom.

From a socioeconomic perspective, the removal of the lower three pairs of hooks would make this fishery more efficient because it would save time. Due to the layout of this fishing gear, these lower hooks often get entangled, either to each other or to the bottom substrate. Not only is time wasted untangling the gear, but this also often causes the longline to break due to fouling on the bottom. Time would also be saved because of the reduction in the number of discard specimens that would have to be removed from the hooks. Thus, without these lower hooks, less time would be wasted handling the longline and fewer gear breaks would occur.

At a direct economic level, the removal of these hooks (six hooks in each set of 40) would represent a $15 \%$ reduction in the total number of hooks and bait. In addition to savings in hook and bait cost, there would also be savings in terms of time spent baiting the hooks.

In conclusion, we propose the removal of the lower three pairs of hooks in the hake semipelagic near-bottom longline while maintaining the position above the bottom of the remaining hooks. This modification would substantially reduce bycatch of elasmobranchs, with a minimal decrease in European hake catches. Significant benefits in terms of handling, gear loss, expenditure on bait and hooks and in time saved would result from this simple modification of the gear.

\section{REFERENCES}

1. Direcção-Geral das Pescas e Aquicultura. Recursos Da Pesca. Série Estatística, 1998. Direcção-Geral das Pescas e Aquicultura, Lisboa. 1999.

2. Lopes RJ, Lafuente MMV, Regueiro JCS, Rosa C, Gil DG, Malvido CI. Study on the Bioeconomic Management and Commercialisation of Hake. Final Report. Commission of the European Communities, DG XIVID 1996, 94/80. Commission of the European Communities, Évora. 1996.

3. Bonfil RS, Anda DF, Mena RA. Shark fisheries in Mexico. The case of Yucatan as an example. In: Pratt HL, Gruber SH, Taniuchi T (eds). Elasmobranchs as Living Resources: Advances in the Biology, Ecology, Systematics, and the Status of the Fisheries, NOAA Technical Report NMFS 90. US Department of Commerce, Seattle. 1990; 427-441.

4. Campbell D, Battaglene T, Shafron W. Economics of resource conservation in a commercial shark fishery. Aust. J. Mar. Freshw. Res. 1992; 43: 251-262.

5. Hurley PCF. A review of the fishery for pelagic sharks in Atlantic Canada. Fish. Res. 1998; 39: 107-113.

6. Stevens JD, Bonfil R, Dulvy NK, Walker PA. The effects of fishing on sharks, rays, and chimaeras (chondrichthyans), and the implications for marine ecosystems. ICES J. Mar. Sci. 2000; 57: 476-494.

7. Buencuerpo V, Ríos S, Morón J. Pelagic sharks associated with the swordfish, Xiphias gladius, fishery in the eastern North Atlantic Ocean and the Strait of Gibraltar. Fish. Bull. 1998; 96: 667-685.

8. Mckinnell S, Seki MP. Shark bycatch in the Japanese high seas squid driftnet fishery in the North Pacific Ocean. Fish. Res. 1998; 39: 127-138.

9. Francis MP. New Zealand shark fisheries: Development, size and management. Mar. Freshw. Res. 1998; 49: 579591.

10. Yudin KG, Cailliet GM. Age and growth of the gray smoothhound, Mustelus californicus, and the brown smoothhound, M. henlei, sharks from Central California. Copeia 1990; 1: 191-204.

11. Wintner SP, Cliff G. Age and growth determination of the white shark, Carcharodon carcharias, from the east coast of South Africa. Fish. Bull. 1999; 97: 153-169.

12. Pratt HL, Casey JG. Shark reproductive strategies as a limiting factor in directed fisheries, with a review of Holden's method of estimating growth-parameters. In: Pratt HL, Gruber SH, Taniuchi T (eds). Elasmobranchs as Living Resources: Advances in the Biology, Ecology, Systematics, and the Status of the Fisheries, NOAA Technical Report NMFS 90. US Department of Commerce, Seattle. 1990: 97109.

13. Smale MJ, Goosen AJ. Reproduction and feeding of spotted gully shark, Triakis megalopterus, off the Eastern Cape, South Africa. Fish. Bull. 1999; 97: 987-998.

14. Hazin FHV, Oliveira PG, Broadhurst MK. Reproduction of the blacknose shark (Carcharhinus acronotus) in coastal waters off northeastern Brazil. Fish. Bull. 2002; 100: 143148.

15. Arimoto T, Iwasaki T. Vertical distribution of catch in a coastal set-line. Bull.Jpn. Soc. Sci. Fish. 1983; 49: 1479-1486.

16. Arimoto T. Interspecific competition among demersal fishes in catch distribution of coastal set-line. Bull.Jpn. Soc. Sci. Fish. 1984; 50: 205-210. 
17. Erzini K, Gonçalves JMS, Bentes L, Lino PG, Cruz J. Species and size selectivity in a multispecies Portuguese artisanal longline fishery. ICES J. Mar. Sci. 1996; 53: 811-819.

18. Erzini K, Gonçalves JMS, Bentes L, Lino PG. Fish mouth dimensions and size selectivity in a Portuguese longline fishery. J. Appl. Ichthyol. 1997; 13: 41-44.

19. Erzini K, Gonçalves JMS, Bentes L, Lino PG, Ribeiro J. Species and size selectivity in a 'red' sea bream longline métier in the Algarve (southern Portugal). Aquat. Liv. Res. 1998; 11: $1-11$.

20. Erzini K, Gonçalves JMS, Bentes L, Lino PG, Ribeiro J. Catch composition, catch rates and size selectivity of three longline métiers in the Algarve (southern Portugal). Bol. Inst. Esp. Oceanogr. 1999; 15: 313-323.

21. Erzini K, Gonçalves JMS, Bentes L, Lino PG, Ribeiro J. The hake deepwater semi-pelagic ('pedra-bola') longline fishery in the Algarve (southern Portugal). Fish. Res. 2001; 51: 327336.

22. Bjordal $\AA$, Løkkeborg S. Longlining. Fishing News Books, Oxford. 1996.

23. Russell GM, Gutherz EJ, Barans CA. Evaluation of demersal longline gear off South Carolina and Puerto Rico with emphasis on deep-water reef fish stocks. Mar. Fish. Rev. 1988; 50: 26-31.

24. Alheit J, Pitcher TJ. Hake. Fisheries, Ecology and Markets. Chapman \& Hall, London. 1994.

25. Santos J, Borges T. Trophic relationships in deep-water fish communities off Algarve, Portugal. Fish. Res. 2001; 51: 337341.

26. Huse I, Soldal AV. An attempt to improve size selction in pelagic longline fisheries for haddock. Fish. Res. 2000; 48: 43-54.

27. Willis TJ, Millar RB. Modified hooks reduce incidental mortality of snapper (Pagrus auratus: Sparidae) in the New Zealand commercial longline fishery. ICES J. Mar. Sci. 2001; 58: 830-841.

28. Goodyear CP. An analysis of the possible utility of time-area closures to minimize billfish by-catch by US pelagic longlines. Fish. Bull. 1999; 97: 243-255.

29. Matsuoka T, Kasu J, Nagaleta H. Catch and fish-loss model for vertical longline fishing with particular emphasis on injury of unharvested fish. Fish. Sci. 1995; 61: 760-765. 